\title{
A Mechanical Model for CCK-Induced Acalculous Gallbladder Pain
}

\author{
W. G. Li, ${ }^{1}$ X. Y. Luo, ${ }^{1}$ N. A. Hill,${ }^{1}$ R. W. Ogden, ${ }^{1}$ A. Smythe, ${ }^{2}$ A. Majeed, ${ }^{2}$ and N. Bird ${ }^{2}$ \\ ${ }^{1}$ School of Mathematics and Statistics, University of Glasgow, Glasgow G12 8QW, UK; and ${ }^{2}$ Academic Surgical Unit, \\ Royal Hallamshire Hospital, Sheffield S10 2JF, UK
}

(Received 12 August 2010; accepted 8 November 2010)

Associate Editor Peter E. McHugh oversaw the review of this article.

\begin{abstract}
This study investigates the potential correlation between acalculous biliary pain and mechanical stress during the bile-emptying phase. This study is built on the previously developed mathematical model used to estimate stress in the gallbladder wall during emptying [Li, W. G., X. Y. Luo, et al. Comput. Math. Methods Med. 9(1):27-45, 2008]. Although the total stress was correctly predicted using the previous model, the contribution from patient-specific active stress induced by the cholecystokinin (CCK) test was overlooked. In this article, we evaluate both the active and passive components of pressure in a gallbladder, which undergoes isotonic refilling, isometric contraction and emptying during the infusion of CCK. The pressure is estimated from in vivo ultrasonographical scan measurements of gallbladder emptying during CCK tests, assuming that the gallbladder is a thin ellipsoidal membrane. The passive stress is caused by the volume and shape changes during refilling at the gallbladder basal pressure, whereas the active stress arises from the pressure rise during the isometric gallbladder contraction after the CCK infusion. The effect on the stress estimates of the gallbladder to the liver is evaluated to be small by comparing numerical simulations of a gallbladder model with and without a rigid 'flat top' boundary. The model was applied to 51 subjects, and the peak total stress was found to have a strong correlation with the pain stimulated by CCK, as measured by the patient pain score questionnaires. Consistent with our previous study for a smaller sample, it is found that the success rate in predicting of CCK-induced pain is over $75 \%$.
\end{abstract}

Keywords-Gallbladder, Active stress, Passive stress, Acalculous biliary pain, Emptying, Refilling, Isometric contraction, Isotonic refilling, CCK.

\section{INTRODUCTION}

The human gallbladder is a small pear-shaped organ on the underside of the liver that is used to store bile. Bile is made in the liver and is stored in the gallbladder

Address correspondence to X. Y. Luo, School of Mathematics and Statistics, University of Glasgow, Glasgow G12 8QW, UK. Electronic mail: x.y.luo@maths.gla.ac.uk until it is needed to help the digestion of fat. Gallbladder disease is a common condition that affects both women and men. The symptoms vary widely from discomfort to severe pain which mainly begins after food intake. In severe cases, the patient can suffer from jaundice, nausea and fever. When this happens, gallbladder removal (cholestectomy) via keyhole surgery is usually recommended.

The most common cause of gallbladder disease is the presence of gallstones. However, it is common to have stones in the gallbladder that cause no symptoms. On the other hand, a proportion of people do suffer from severe acalculous (i.e. without gallstones) biliary pain. The decision to surgically remove the gallbladder is made when patients have symptoms (pain), not if they have gallstones.

The burden of gallbladder disease has become epidemic worldwide in recent years. It is the most common abdominal reason for admission to hospital in developed countries and accounts for an important part of healthcare expenditure. The disease in the U.S. afflicts some 6.3 million men and 14.2 million women aged 20-74 years, making it the most costly digestive disorder at an estimated $\$ 6.5$ billion annually. The extent of gallbladder disease in Europe is similar to the U.S., with a median prevalence in large population surveys, ranging from 5.9 to $21.9 \%{ }^{4}{ }^{4}$ Around 5.5 million people have gallstones in the United Kingdom, and over 50,000 cholecystectomies are performed each year. ${ }^{4}$ Gallbladder attacks are extremely painful and can cause life-threatening infections. Most people who have a cholecystectomy have no problems afterwards. Unfortunately, a small percentage of people $(10-15 \%)$ have post-cholecystectomy complications. About $20 \%$ who have had their gallbladder removed had diarrhoea afterwards.

Of a major concern is that not all patients benefit from the cholestectomy, and the symptoms continue even though the gallbladder has been removed. It has 
been reported that only $50 \%$ of acalculous patients are free from pain symptoms after cholecystectomy. ${ }^{50,51} \mathrm{~A}$ challenging task is to identify effectively these patients to reduce unnecessary surgery. Bile ejection fraction (EF), whereby the gallbladder-emptying contraction is measured by its volume change, has been used clinically, but it has been reported to be unreliable. ${ }^{13}$ The cholecystokinin (CCK) provocation test has also been used as a routine test to identify acalculous biliary pain clinically, ${ }^{9}$ and to select a group of patients who might benefit from cholecystectomy. ${ }^{55}$ However, the effectiveness of such a test is yet to be established. ${ }^{13,50}$

The fundamental issue is to understand the underlying mechanisms of gallbladder pain, ${ }^{26}$ which remains a challenge. Using a mechanical model $\mathrm{Li}$ et $a l .{ }^{25}$ predicted that the peak total stress in the gallbladder wall has a strong correlation with the pain provoked by the CCK test performed on 37 subjects. As the mechanical stresses in the model are estimated entirely from non-invasive ultrasonographical routine measurements, this approach may be readily developed as a useful routine additional diagnostic tool if the concept of the stress-pain correlation can be validated.

In this study, we aim to develop further our earlier model by investigating the patient-specific active stress induced by $\mathrm{CCK}$, which was previously taken to be the same for all subjects. ${ }^{25}$ It has been shown that the active stress of gallbladder smooth muscle due to a stimulus is highly time-dependent ${ }^{7,56}$ and probably quite patient specific. ${ }^{18}$ Even though the gallbladder pressure-volume response to various continuous intravenous infusions of CCK has been observed ${ }^{42}$ and a dynamic method has been proposed for describing gallbladder tone in an in situ baboon model,${ }^{43}$ to date, very few studies have aimed at estimating the action stress in primate gallbladder smooth muscles.

On the other hand, extensive studies exist for cardiac smooth muscles. There are two approaches for modelling active force or stress in cardiac smooth muscle during the systolic phase. ${ }^{47-49}$ The first is the structural method where the active stress developed can be determined from the complex structure of the heart and muscle fibre orientations by developing a sophisticated constitutive formulation for the heart muscle. This approach has been employed by Streeter et al. ${ }^{52}$ for instance. A comprehensive review of this method was provided by Hunter and Smaill. ${ }^{19}$ The second is a global approach where active stress is considered as a continuous body force along the proper three orthogonal coordinate axes, rather than the force generated by a finite number of fibres. ${ }^{47-49}$ Since this approach does not involve the complex structure of the myocardium, it provides a simple and effective tool for those who are interested only in the macro-mechanics of heart muscle contraction.
In this article, we employ the global approach and analyse the active stress in gallbladder smooth muscle. Furthermore, the analytical solution for the stresses was compared with a thin shell numerical model of the gallbladder using the ADINA 8.5.2 finite element package. The ADINA model also enables us to check the model of a gallbladder with a flat top, i.e. the effect of liver attachment, on the stress level. Finally, the predicted stresses, passive, active and total peak values were compared with the clinically recorded data of pain due to the CCK test in the case of 51 subjects. It is found that the peak total stress consistently correlates strongly with the CCK-induced pain.

\section{MECHANICAL MODELS}

\section{Model Assumptions}

In the mechanical model, we make the following assumptions: (1) The gallbladder is considered to be a thin-walled elastic ellipsoid membrane subject to isotropic contraction; (2) The emptying and refilling phases of the gallbladder are supposed to be quasi-static and inertia forces are neglected; and (3) Gallbladder smooth muscle is incompressible, isotropic, elastic and homogenous. These are based on the facts that the gallbladder wall is thin $(\sim 1-2 \mathrm{~mm})$ in normal physiological conditions and that the bile flow is usually slow with a Reynolds number $\operatorname{Re}<20 .^{24,35}$ It has been reported that human gallbladder isolated smooth muscle cells have a mean basal length $42 \pm 1.2 \mu \mathrm{m}$ in the patients with gallstones, $42 \pm 1.1 \mu \mathrm{m}$ in those with black pigment stones and $42 \pm 1.3 \mu \mathrm{m}$ in the healthy subjects. ${ }^{7,56}$ However, these cells were distributed in the gallbladder wall without preferred orientations. Further, the muscle layer of the canine gallbladder wall was found to be a three-dimensional meshwork of smooth muscle bundles which appear loosely and irregularly arranged on the mucosal aspect and consolidate to form a homogeneous plate-like layer on the serosal aspect. ${ }^{27}$

\section{CCK Provocation Test}

In this article, we make use of the CCK provocation test carried out in the routine assessment of 51 patients with acalculous biliary pain, who had experienced repeated attacks of biliary-type pain in the absence of gallstones or any obvious causative findings. ${ }^{50}$ Acalculous biliary pain is classically associated with fatty food intake that leads to the release of CCK which causes gallbladder contraction. This is the rationale for the CCK Provocation Test. ${ }^{50}$ The study was commenced in 1994 at which time the senior author (now deceased) determined that the CCK provocation test was in clinical use and, therefore, did not require addressing any ethical issues. 
After an overnight fast, the patients were given an intravenous infusion of saline (control) followed by an intravenous infusion of CCK $(0.05 \mu \mathrm{g} / \mathrm{kg}$ body weight). Ultrasonography of the gallbladder was used to monitor changes in shape, initial volume, change of volume and wall thickness at 5- or 15-min intervals for $60 \mathrm{~min}$. The patients were unaware as to which substance was being given, and the test was only considered positive when the patient's usual 'gallbladder' pain was reproduced following CCK infusion..$^{50,51}$ Figures $1 \mathrm{a}$ and $1 \mathrm{~b}$ show schematically the pressure and volume against time during the CCK provocation test. At the beginning of the refilling phase (point $\mathrm{C}$ ), the sphincter of Oddi is closed, the gallbladder is fasted, and the volume and pressure are at the minimum basal levels. Between point $\mathrm{C}$ and the end of the refilling (point A), a small but positive pressure difference between the liver and the gallbladder exists ${ }^{17}$ which allows the hepatic bile to be secreted slowly into the gallbladder. The refilling time (from $\mathrm{C}$ to $\mathrm{A}$ ) scale is usually the time lapse between two meals, and is often more than six times longer than the emptying time. During this time, gallbladder relaxes, and the internal pressure $p_{\mathrm{e}}$ may be considered to be constant i.e. $p_{\mathrm{e}}=11 \mathrm{mmHg} .{ }^{10}$ Such an assumption is in line with the experimental observation of human gallbladder pressure made by Body et al. ${ }^{5}$ In other words, refilling is an isotonic process.

At the point $\mathrm{A}$, CCK is infused, causing the gallbladder to contract. The pressure in the gallbladder rises rapidly up to point $\mathrm{B}$ in about $5 \mathrm{~min}$ (which is the time CCK needs to reach the gallbladder after the intravenous infusion), and exceeds the pressure in the common bile duct. In the meantime, CCK also acts on the sphincter of Oddi, which responds by relaxing and opening up. As a result, the pressure in the common bile duct is lowered further. The pressure drop between the gallbladder and the common bile duct is sufficiently high that the bile flow direction is reversed, and the emptying phase begins (point B). Emptying lasts for about $30 \mathrm{~min}$ in the normal situation and finishes at point C. For a healthy subject, the ejection fraction $(E F)$ is expected to reach about $70 \%$ of the fasting volume $V_{0}$ at the end of emptying, or beginning of the refilling. The refilling and emptying phases can also be represented by the $p-V$ diagram shown in Fig. 1c.

\section{Estimation of the Pressure from Volume Measurements}

As we cannot measure the pressure non-invasively, here we estimate it based on measurements of the changes in gallbladder volume. During the emptying phase, bile flows out and the gallbladder volume decreases. Since images of the gallbladder and its volume have been recorded at several time instances after
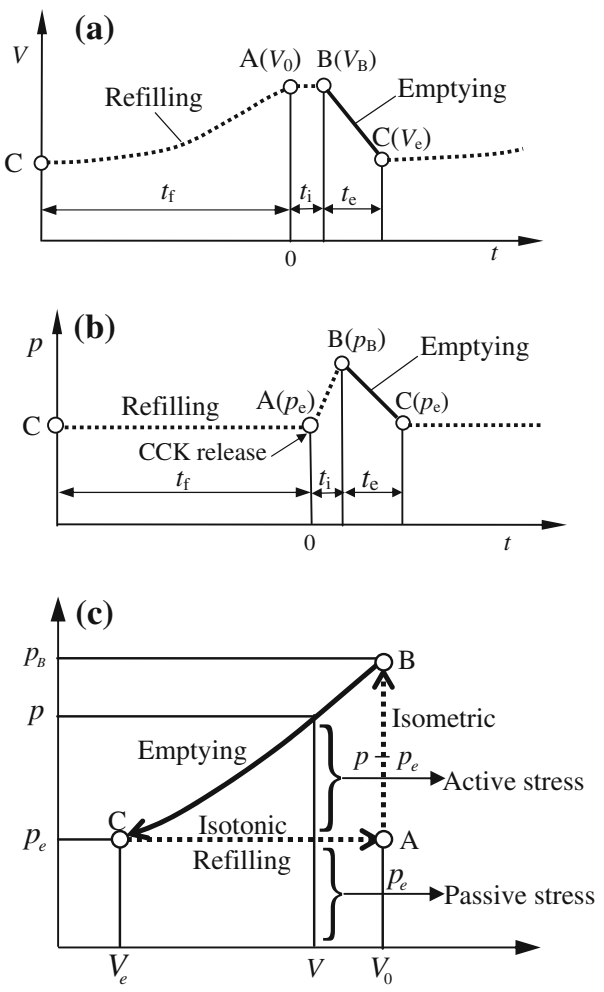

FIGURE 1. During refilling and CCK-induced emptying, the variation in the volume and pressure of the gallbladder with time are shown in (a) and (b), respectively. The corresponding pressure-volume diagram is shown in (c). Note only the emptying phase, i.e. the solid curves in (a) and (b), is investigated.

point $\mathrm{B}$, it is possible to estimate the corresponding pressure using a Windkessel type model ${ }^{25}$ that gives

$$
p=p_{\mathrm{d}}+\left(p_{\mathrm{e}}-p_{\mathrm{d}}\right) e^{\frac{t_{\mathrm{e}}+t_{\mathrm{i}}-t}{R C}}, \quad t \in\left[t_{\mathrm{i}}, t_{\mathrm{e}}+t_{\mathrm{i}}\right]
$$

where $p_{\mathrm{d}}$ is the pressure in the duodenum, $p_{\mathrm{d}}=6$ $\mathrm{mmHg},{ }^{25}$ and the volume during the emptying is given by

$$
V=C\left(p_{\mathrm{e}}-p_{\mathrm{d}}\right) e^{\frac{t_{\mathrm{e}}+t_{\mathrm{i}}-t}{R C}}+\gamma, \quad t \in\left[t_{\mathrm{i}}, t_{\mathrm{e}}+t_{\mathrm{i}}\right],
$$

where $\gamma=V_{\mathrm{e}}-C\left(p_{\mathrm{e}}-p_{\mathrm{d}}\right), V_{\mathrm{e}}$ is the volume when emptying is finished, $V_{\mathrm{e}}=0.3 V_{0}$, and $t_{\mathrm{e}}$ is the emptying time for $E F$ to reach $70 \%$ ( $t_{\mathrm{e}}$ much longer than 30 min would indicate a poor emptying), $R$ is the flow resistance, and $C$ is the wall compliance, taken to be $2.731 \mathrm{~mL} / \mathrm{mmHg} .{ }^{31}$ For a given volume change over time, it is easy to estimate that

$$
R=\frac{t_{\exp }-t_{\mathrm{i}}}{C \ln \left[\left(V_{0}-\gamma\right) /\left(V_{\exp }-\gamma\right)\right]}, \quad t_{\exp } \in\left[t_{\mathrm{i}}, t_{\mathrm{e}}+t_{\mathrm{i}}\right],
$$

and

$$
\begin{aligned}
t_{e}= & \frac{\ln \left[\left(V_{0}-\gamma\right) /\left(V_{\mathrm{e}}-\gamma\right)\right]}{\ln \left[\left(V_{0}-\gamma\right) /\left(V_{\exp }-\gamma\right)\right]}\left(t_{\exp }-t_{\mathrm{i}}\right), \\
& t_{\exp } \in\left[t_{\mathrm{i}}, t_{\mathrm{e}}+t_{\mathrm{i}}\right] .
\end{aligned}
$$

where $V_{\exp }$ is the volume measured at a specific time, $t_{\text {exp }}$, during emptying. 


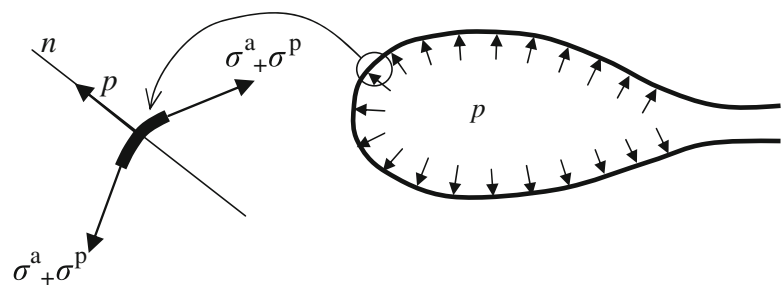

FIGURE 2. The gallbladder is subject to an increased internal pressure during CCK infusion, which generates the active and passive stresses $\sigma^{a}, \sigma^{p}$ inside the muscle wall.

\section{Modelling the Membrane Stress in the Gallbladder Wall}

Figure 2 sketches a cross section of a gallbladder subject to an internal bile pressure $p$ which gives rise to a passive stress $\sigma^{p}$ and an active stress $\sigma^{a}$. Note that active stress is due to CCK stimulus only, while the passive stress is caused by volume changes at constant pressure. In fact, active stress can be triggered by various stimuli, including an electric field stimulation, ${ }^{36,46}$ ionic action potential, ${ }^{40,57} \mathrm{CCK}^{6,20,23,32,41,45}$ and ACh. ${ }^{6,21,37,41,53}$ The basic mechanism of these stimuli is to establish an effective $\mathrm{Ca}^{2+}$ flux across gallbladder smooth muscle cell membranes to activate myosin light chain phosphorylation; subsequently, latch cross-bridges start to form in the cells and generate contraction. ${ }^{53,54}$

\section{Stress Modelling}

If we assume that the gallbladder maintains an ellipsoidal shape during the refilling and emptying phases as in Li et al., ${ }^{25}$ then the stress components $\left(\sigma_{\theta}, \sigma_{\phi}, \tau_{\theta \phi}\right)$ in the spherical coordinate system $(R, \phi$, $\theta)$ under a net internal pressure $p$ are expressed $\mathrm{as}^{34}$ :

$$
\left\{\begin{array}{l}
\sigma_{\theta}=p F_{\theta}\left(h_{\mathrm{GB}}, D_{3}, k_{1}, k_{2}, \phi, t\right) \times F_{\mathrm{n}}\left(k_{1}, k_{2}, \theta, \phi, t\right) \\
\sigma_{\phi}=p F_{\phi}\left(h_{\mathrm{GB}}, D_{3}, k_{1}, k_{2}, \theta, \phi, t\right) \times \overline{F_{\mathrm{n}}\left(k_{1}, k_{2}, \theta, \phi, t\right)} \\
\tau_{\theta \phi}=p F_{\tau}\left(h_{\mathrm{GB}}, D_{3}, k_{1}, k_{2}, \theta, \phi, t\right)
\end{array} .\right.
$$

Here, $F_{\theta}, F_{\phi}, F_{\tau}$ and $F_{\mathrm{n}}$ are the functions of time describing the instantaneous shape change of a gallbladder:

$$
\left\{\begin{array}{l}
F_{\theta}\left(h_{\mathrm{GB}}, D_{3}, k_{1}, k_{2}, \phi, t\right)=\frac{D_{3} k_{1} k_{2}}{4 h_{\mathrm{GB}}}\left(1-\frac{k_{1}^{2}-k_{2}^{2}}{k_{1}^{2} k_{2}^{2}} \cos 2 \phi\right), \\
F_{\phi}\left(h_{\mathrm{GB}}, D_{3}, k_{1}, k_{2}, \theta, \phi, t\right) \\
\quad=\frac{D_{3}}{4 k_{1} k_{2} h_{\mathrm{GB}}}\left[k_{1}^{2} k_{2}^{2}+\left(k_{1}^{2}+k_{2}^{2}-2 k_{1}^{2} k_{2}^{2}\right) \sin ^{2} \theta\right. \\
\left.\quad+\left(k_{1}^{2}-k_{2}^{2}\right) \cos ^{2} \theta \cos 2 \phi\right], \\
F_{\tau}\left(h_{\mathrm{GB}}, D_{3}, k_{1}, k_{2}, \theta, \phi, t\right) \\
\quad=\frac{D_{3}}{4 k_{1} k_{2} h_{\mathrm{GB}}}\left(k_{1}^{2}-k_{2}^{2}\right) \cos \theta \sin 2 \phi, \\
F_{\mathrm{n}}\left(k_{1}, k_{2}, \theta, \phi, t\right)=\frac{\sqrt{k_{1}^{2} \cos ^{2} \theta \cos ^{2} \phi+k_{2}^{2} \cos ^{2} \theta \sin ^{2} \phi+\sin ^{2} \theta}}{\sqrt{k_{1}^{2} \sin ^{2} \phi+k_{2}^{2} \cos ^{2} \phi}},
\end{array}\right.
$$

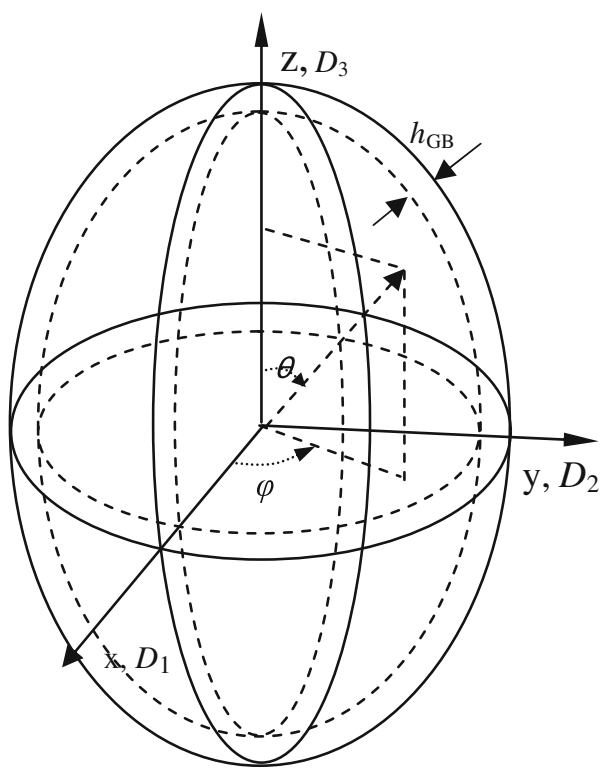

FIGURE 3. The coordinate system for the ellipsoidal model of the gallbladder.

where $k_{1}(t)=D_{1} / D_{3}, k_{2}(t)=D_{2} / D_{3}, D_{1}(\mathrm{t}), D_{2}(t)$ are the diameters along the two minor axes at time $t$, $D_{3}(t)$ is the diameter along the major axis at time $t$ (see Fig. 3), and $h_{\mathrm{GB}}$ is the gallbladder wall thickness (assumed to be constant).

\section{Passive Stress}

The passive stress in the gallbladder wall subject to the basal pressure is thus

$$
\left\{\begin{array}{l}
\sigma_{\theta}^{p}=p_{\mathrm{e}} F_{\theta}\left(h_{\mathrm{GB}}, D_{3}, k_{1}, k_{2}, \phi, t\right) \times F_{\mathrm{n}}\left(k_{1}, k_{2}, \theta, \phi, t\right) \\
\sigma_{\phi}^{p}=p_{\mathrm{e}} F_{\phi}\left(h_{\mathrm{GB}}, D_{3}, k_{1}, k_{2}, \theta, \phi, t\right) \times \overline{F_{\mathrm{n}}\left(k_{1}, k_{2}, \theta, \phi, t\right)} \\
\tau_{\theta \phi}^{p}=p_{\mathrm{e}} F_{\tau}\left(h_{\mathrm{GB}}, D_{3}, k_{1}, k_{2}, \theta, \phi, t\right)
\end{array} .\right.
$$

\section{Active Stress}

At point A the CCK is applied; it reaches the gallbladder in about 5 min (point B), and the gallbladder begins to contract. Subsequently, the internal pressure increases. This response is almost instantaneous (within 15s), so the process is considered to be isometric. For isometric contractions, it has been found that the active force of smooth muscles has an exponential form. ${ }^{29}$ Hence, we have

$$
\left\{\begin{array}{l}
p=p_{e} e^{\lambda t} \\
V_{\mathrm{B}} \approx V_{0}
\end{array}\right.
$$

where $p_{\mathrm{e}}<p<p_{\mathrm{B}}, \lambda=\ln \left(p_{\mathrm{B}} / p_{\mathrm{e}}\right) / t_{\mathrm{i}}, V_{\mathrm{B}}$ and $p_{\mathrm{B}}$ are the gallbladder volume and pressure at point $\mathrm{B}$, and $\lambda$ is a constant. From (1), it follows that $p_{\mathrm{B}}$ is 


$$
p_{\mathrm{B}}=p_{\mathrm{d}}+\left(p_{\mathrm{e}}-p_{\mathrm{d}}\right) e^{\frac{t_{\mathrm{e}}}{R C}} .
$$

The pressure drop, $p_{\mathrm{B}}-p_{\mathrm{e}}$, during emptying does work on the bile and delivers the bile into the duodenum. The amount of this work is represented by the area $\mathrm{ABC}$, as shown in Fig. 1c. Further, the pressure difference is due to the peak active stress at point $\mathrm{B}$, with the stress components given by:

$$
\left\{\begin{aligned}
\sigma_{\theta}^{a}= & \left(p_{\mathrm{B}}-p_{\mathrm{e}}\right) F_{\theta}\left(h_{\mathrm{GB}}, D_{3 \mathrm{~B}}, k_{1 \mathrm{~B}}, k_{2 \mathrm{~B}}, \phi, t\right) \\
& \times F_{\mathrm{n}}\left(k_{1 \mathrm{~B}}, k_{2 \mathrm{~B}}, \theta, \phi, t\right), \\
\sigma_{\phi}^{a}= & \left(p_{\mathrm{B}}-p_{\mathrm{e}}\right) F_{\phi}\left(h_{\mathrm{GB}}, D_{3 \mathrm{~B}}, k_{1 \mathrm{~B}}, k_{2 \mathrm{~B}}, \theta, \phi, t\right), \\
& \times \frac{1}{F_{\mathrm{n}}\left(k_{1 \mathrm{~B}}, k_{2 \mathrm{~B}}, \theta, \phi, t\right)} \\
\tau_{\theta \phi}^{a}= & \left(p_{\mathrm{B}}-p_{\mathrm{e}}\right) F_{\tau}\left(h_{\mathrm{GB}}, D_{3 \mathrm{~B}}, k_{1 \mathrm{~B}}, k_{2 \mathrm{~B}}, \theta, \phi, t\right),
\end{aligned}\right.
$$

where $k_{1 \mathrm{~B}}=D_{1 \mathrm{~B}} / D_{3 \mathrm{~B}}, \quad k_{2 \mathrm{~B}}=D_{2 \mathrm{~B}} / D_{3 \mathrm{~B}}$. and $D_{1 \mathrm{~B}}=$ $D_{1}\left(t_{\mathrm{i}}\right)$, etc.

\section{The Total Stress}

The components of the total stress in the gallbladder wall are then

$$
\left\{\begin{array}{l}
\sigma_{\theta}=\sigma_{\theta}^{p}+\sigma_{\theta}^{a} \\
\sigma_{\phi}=\sigma_{\phi}^{p}+\sigma_{\theta}^{a} \\
\tau_{\theta \phi}=\tau_{\theta \phi}^{p}+\tau_{\theta \phi}^{a}
\end{array},\right.
$$

and the peak stress, which is shape dependent, is

$$
\sigma_{\max }=\max \left[\sigma_{\theta}, \sigma_{\phi}\right] .
$$

Note that (11) predicts a similar total peak stress to the model derived by $\mathrm{Li}$ et al. ${ }^{25}$; however, significant differences exist in the modelling of both passive and active stresses here. In Li et al., ${ }^{25}$ the same magnitude of the active stress was used for all the subjects, while here both the passive and active stresses are patient dependent, and the proportion of these two types of stresses is modelled correctly by the realization of isometric and isotonic processes occurring during gallbladder emptying and refilling. The active stress induced by the CCK can be used to provide further insights in the smooth muscle cross-bridge cycling kinetics during isometric contraction.

\section{The Pain Threshold}

We derive the stress threshold for pain based on the experimental data on common bile duct inflation by saline ${ }^{14}$ which showed that the average pressure threshold for pain was $p_{\mathrm{CBD}}=35 \mathrm{mmHg}$ in the common bile duct for 33 patients. Thus, the circumferential stress in the duct wall can be estimated as

$$
[\sigma]=\frac{p_{\mathrm{CBD}} d_{\mathrm{CBD}}}{2 h_{\mathrm{CBD}}}=175 \mathrm{mmHg},
$$

where the mean diameter of common bile duct $d_{\mathrm{CBD}}$ is $10 \mathrm{~mm},{ }^{12}$ and the mean thickness of the duct wall
$h_{\mathrm{CBD}}$ is $1 \mathrm{~mm} \cdot{ }^{28}$ Based on this, we predict gallbladder pain whenever

$$
\sigma_{\max } \geq[\sigma] .
$$

Note that Li et al. ${ }^{25}$ used $[\sigma]=200 \mathrm{mmHg}$ under a peak pressure $40 \mathrm{mmHg} .{ }^{33}$ Given that the pain threshold estimated can be highly subjective, the sensitivity of the results to variation in the threshold value is tested in "Gallbladder Pain Prediction" section below.

\section{RESULTS}

\section{Pressure and Stresses}

We have extended our sample size from 37 patients in the previous study ${ }^{25}$ to 51 patients, all with acalculous pain and all having had a CCK provocation test. First, the volume and pressure are derived as functions of time based on volume measurement and Eqs. (1) and (2); these are shown in Figs. $4 \mathrm{a}$ and $4 \mathrm{~b}$ for three selected cases. The initial time is when CCK is applied, and we assume that it reached the gallbladder within 5 min for all subjects. During the isometric contraction, the volume of these gallbladders remains constant, and pressure increases until emptying starts. The corresponding $p-V$ diagrams for these cases are shown in Fig. 5a, with the computed peak passive and active stresses plotted as functions of time in Fig. $5 b$.

Note that the maximum values of the peak stresses, which usually occur in the longitudinal $(\theta)$ direction, do not correspond directly to the maximum pressure: subject 9 has lower peak pressure compared to subject 37, but the former has much higher passive and active stresses due to the geometry of the gallbladder. As the gallbladder size decreases with time in the emptying phase, the passive stress due to the constant basal pressure, $p_{\mathrm{e}}$, decreases as the result of shape changes and a decrease in $D_{3}$; see Eqs. (5) and (6). The active stress also peaks at the isometric contraction just before emptying starts and decays with time afterwards. The variation of passive and active stresses in the gallbladders with time resembles that of myocardial tissue. ${ }^{8}$

The contours of stress components for subject 9 are shown in Fig. 6. It shows that the active stress shares the same pattern as the passive stress. This is not surprising, for although shape changes are allowed in gallbladders during refilling or emptying, they remain as ellipsoids under our modelling assumptions.

\section{Sensitivity to Gallbladder Geometry}

As gallbladders are not entirely ellipsoidal, the question arises as to how sensitive the predicted peak stresses are to this modelling assumption. This is 
(a)
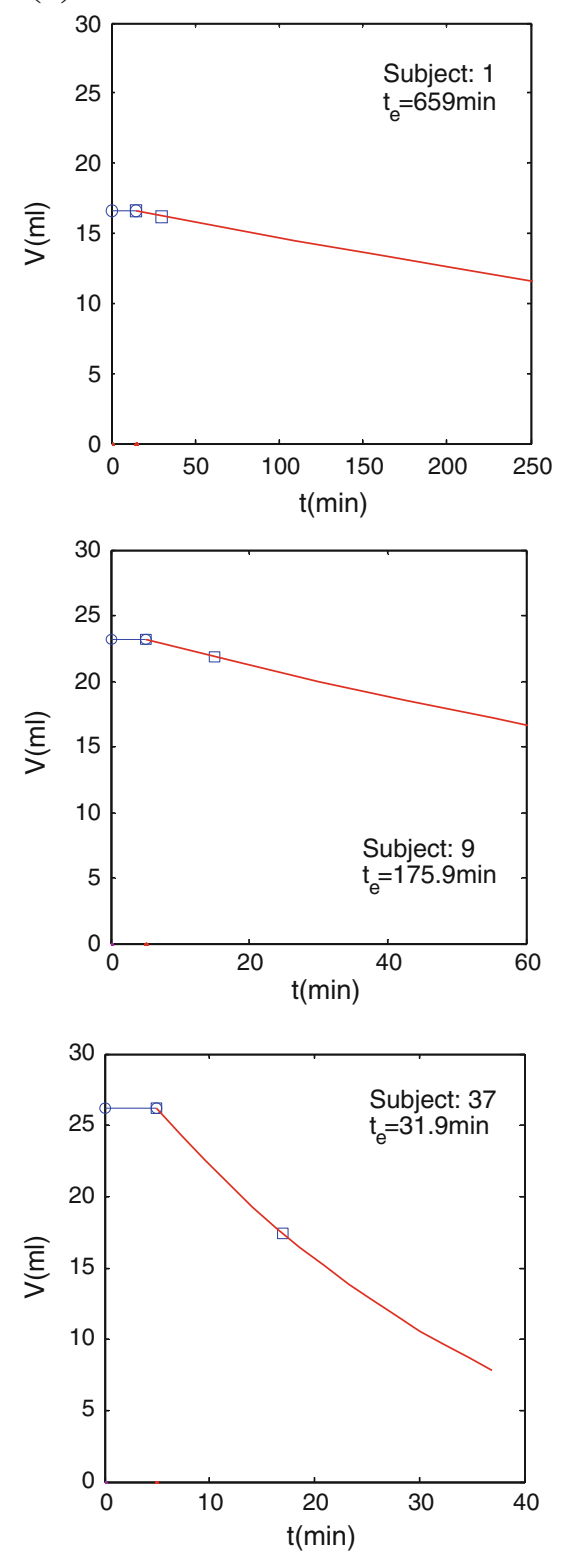

(b)
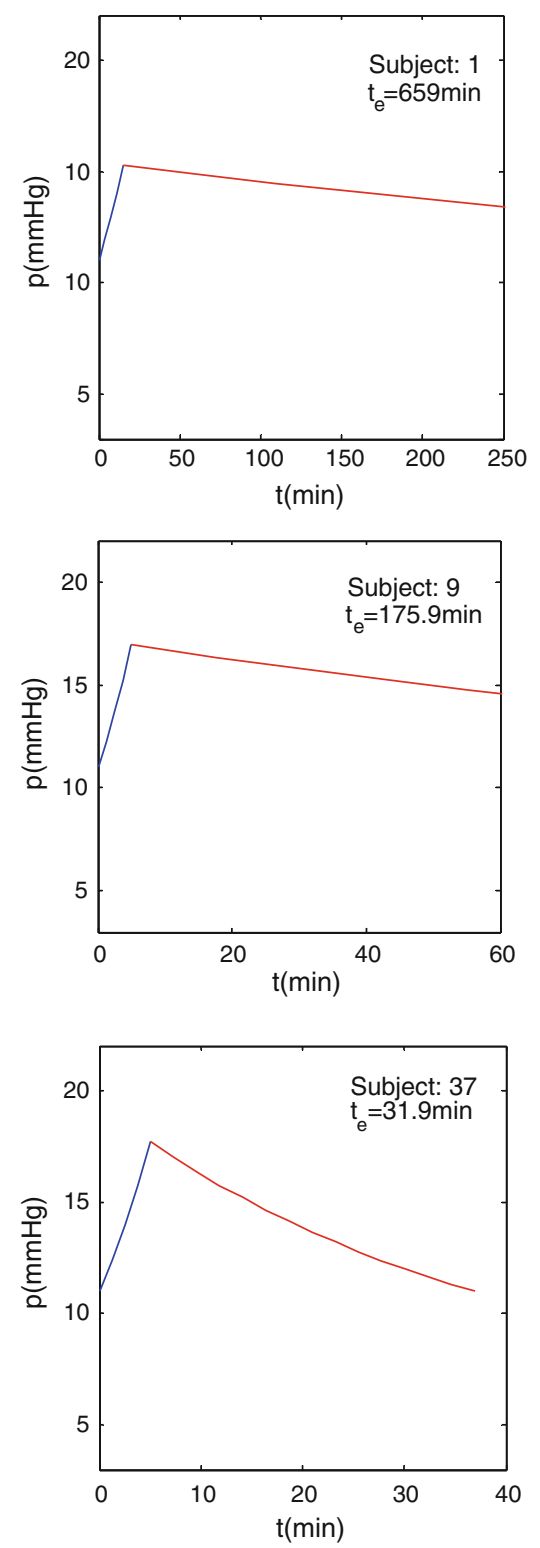

FIGURE 4. Variation of volume (a) and pressure (b) during emptying of the gallbladders of subjects 1,9 and 37 . The circles denote the experimental data during the isometric contraction; and the squares represent the experimental data during emptying. Subject 1 shows very poor emptying and the lowest pressure, whereas subject 37 has very good emptying and the highest pressure.

especially important since more than one third of the top surface of the gallbladder is attached to the liver, resulting in the deformation in this region being restricted. Detailed analysis of geometric changes in the gallbladder requires more sophisticated threedimensional modelling performed on a patient-specific basis, and will require much detailed MRI data than those available from routine clinical scans. Hence, we shall focus on assessing the variation of the peak stresses for a perfect ellipsoid with and without a flat rigid top surface, which conceptually resembles the liver attachment.
We first compare the stress predicted by the analytical model described in "Mechanical Models" section with the numerical result using the Finite Element package ADINA 8.5.2. The chosen test model has the following properties: $D_{1}=D_{2}=40 \mathrm{~mm}, D_{3}=60 \mathrm{~mm}$, thickness $h_{\mathrm{GB}}=2.5 \mathrm{~mm}$. The material is chosen to be homogenous, isotropic and linear, with Young's modulus $E=5 \times 10^{4} \mathrm{~Pa},{ }^{16}$ and Poisson's ratio $\mu=0.45$. The ellipsoid is subject to a pressure of $18 \mathrm{mmHg}$ (2400 Pa). A thin-shell model without bending stiffness is chosen in ADINA 8.5.2. Mesh-independence tests lead to the use of 7000 four-node quadrilateral 
(a)
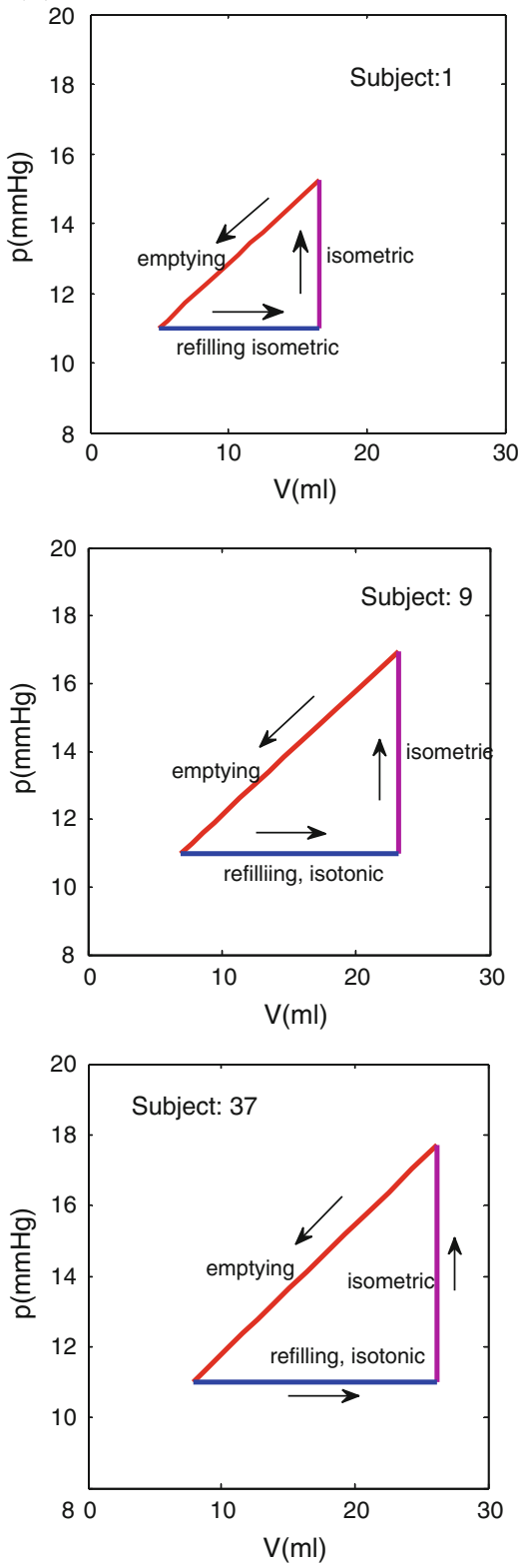

(b)
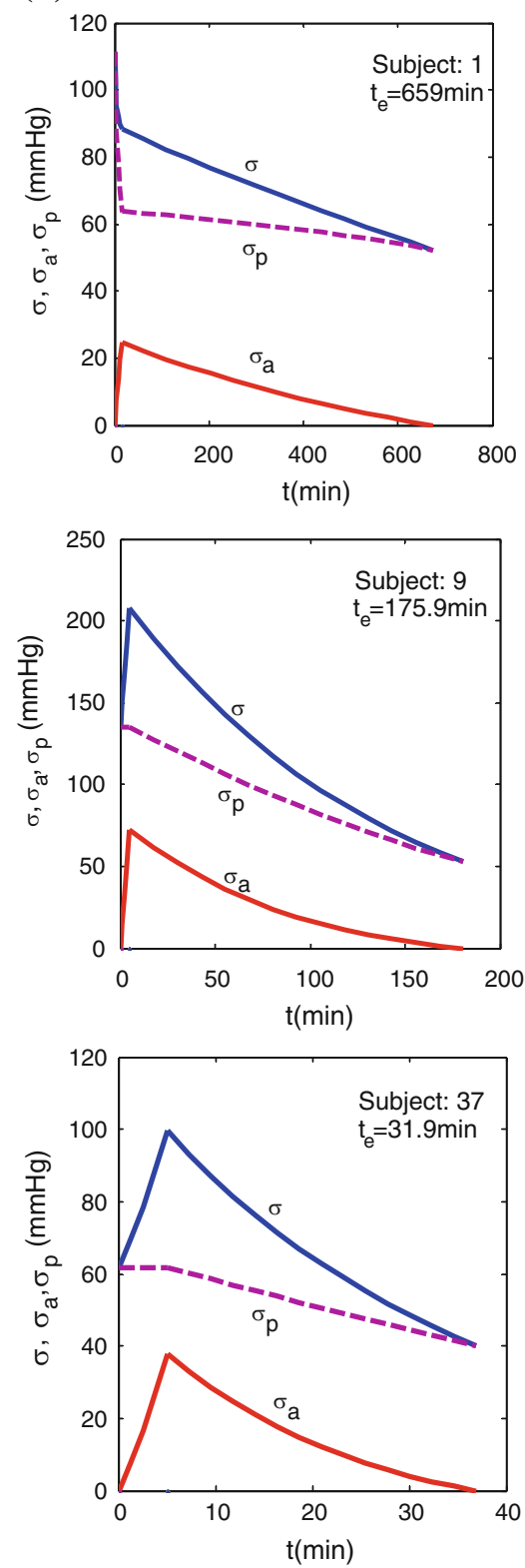

FIGURE 5. Pressure-volume diagram and the peak active $\left(\sigma_{\mathrm{a}}\right)$, passive $\left(\sigma_{\mathrm{p}}\right)$ and total $(\sigma)$ stresses during isometric and emptying phases. The total peak stress in the gallbladder wall of subject 9 has been over $200 \mathrm{mmHg}$.

elements for the numerical model (see the Appendix). A comparison of the stress contours from the analytical prediction and numerical simulation is shown in Fig. 7, with the corresponding peak stress components listed in Table 1. As ADINA uses Cartesian $(x, y, z)$ coordinates, the stress components are now shown as $\sigma_{\mathrm{xx}}, \sigma_{\mathrm{yy}}$ and $\sigma_{\mathrm{zz}}$, the normal stress components in the $x$ - and $y$ - and $z$-directions. Since we only consider the special case when $D_{1}=D_{2}$, the shear stresses $\tau_{\mathrm{xy}}, \tau_{\mathrm{xz}}, \tau_{\mathrm{yz}}$, are all zero.

In general, the analytical prediction agrees well with the numerical solution, although some small degree of discrepancy exists between the numerical and analytical results. This is likely because of the slightly different thin-shell simplifications introduced in the analytical and numerical models. ${ }^{3,34}$ This discrepancy is accepted here since we are only interested in a proof of concept model, aiming to establish the statistical significance of the correlation between peak stress and pain. In this spirit, we also note that the maximum of the wall thickness-diameter ratio $2 h_{\mathrm{GB}} / D_{1}$ is $2.5 / 20$ for a typical gallbladder which is greater than the commonly accepted thin-shell limit of $1 / 20,{ }^{34}$ and the ratio increases significantly when diseased. It is essential that 
0 010 (o) 

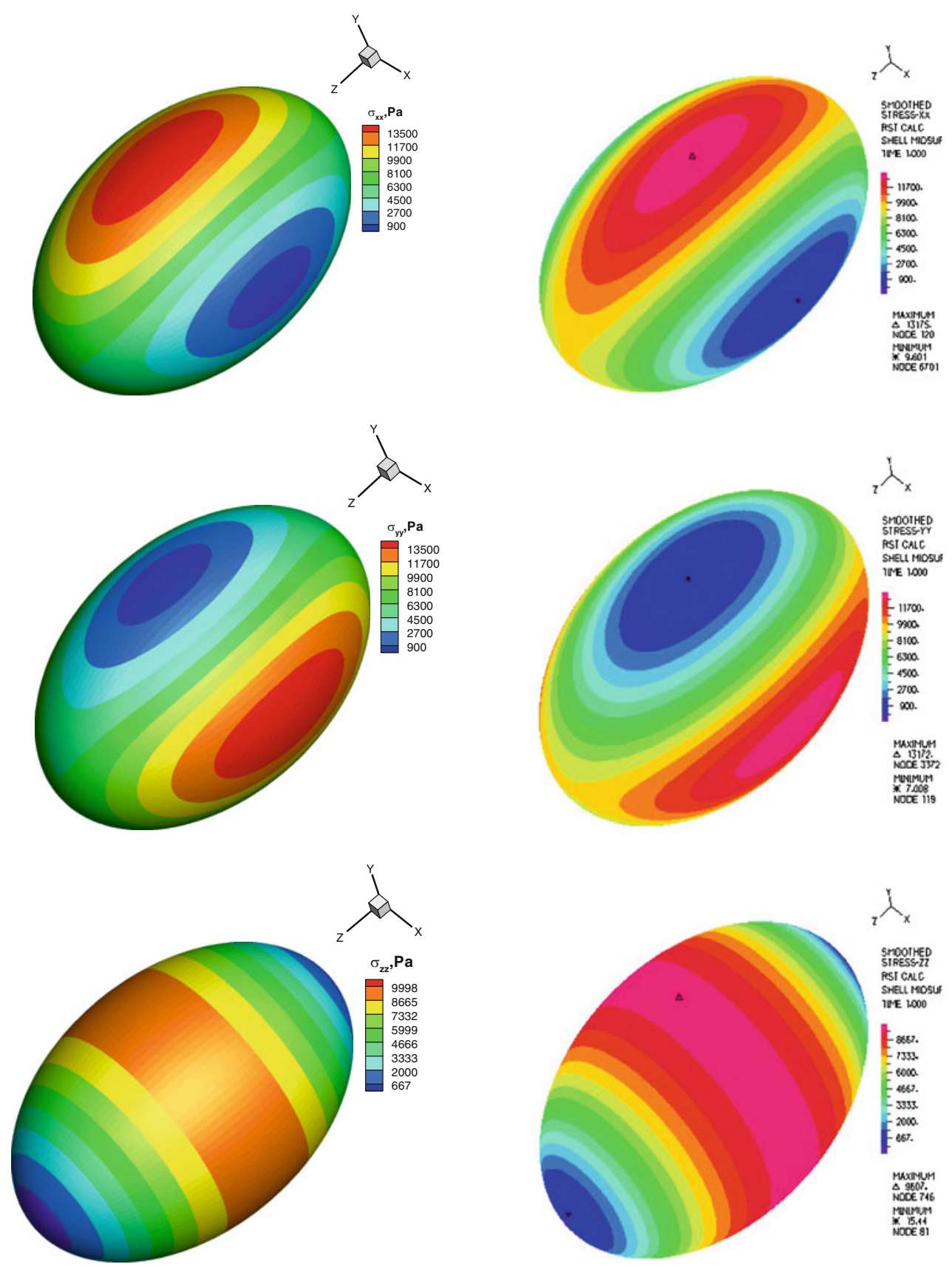

FIGURE 7. Contours of stresses of the test gallbladder model without a flat top, given by analytical (left) and numerical (right) models. Top panel: $\sigma_{\mathrm{xx}}$, middle panel: $\sigma_{\mathrm{yy}}$ and bottom panel: $\sigma_{\mathrm{zz}}$.

TABLE 1. The peak stress components of gallbladder models with and without a flat top.

The peak stress

\begin{tabular}{lccc} 
components & $\sigma_{\mathrm{xx}}^{\mathrm{p}}(\mathrm{Pa})$ & $\sigma_{\mathrm{yy}}^{\mathrm{p}}(\mathrm{Pa})$ & $\sigma_{\mathrm{zz}}^{\mathrm{p}}(\mathrm{Pa})$ \\
\hline Analytical-without flat top & 14,930 & 14,930 & 9599 \\
Numerical-without flat top & 13,175 & 13,172 & 9607 \\
Numerical with 5 mm cut-off & 12,630 & 13,064 & 9495 \\
Numerical with 10 mm cut-off & 12,063 & 13,004 & 9377 \\
\hline
\end{tabular}

\section{Gallbladder Pain Prediction}

The peak stresses at the beginning of emptying, computed for all the 51 subjects, are listed in Table 2 . For reference, the corresponding pressure, the initial gallbladder geometry, and $E F$ estimated at $t=30 \mathrm{~min}$ after CCK infusion, are also listed. Using the stress criterion defined in (14), we can also assess whether the model prediction agrees with the clinical outcome 

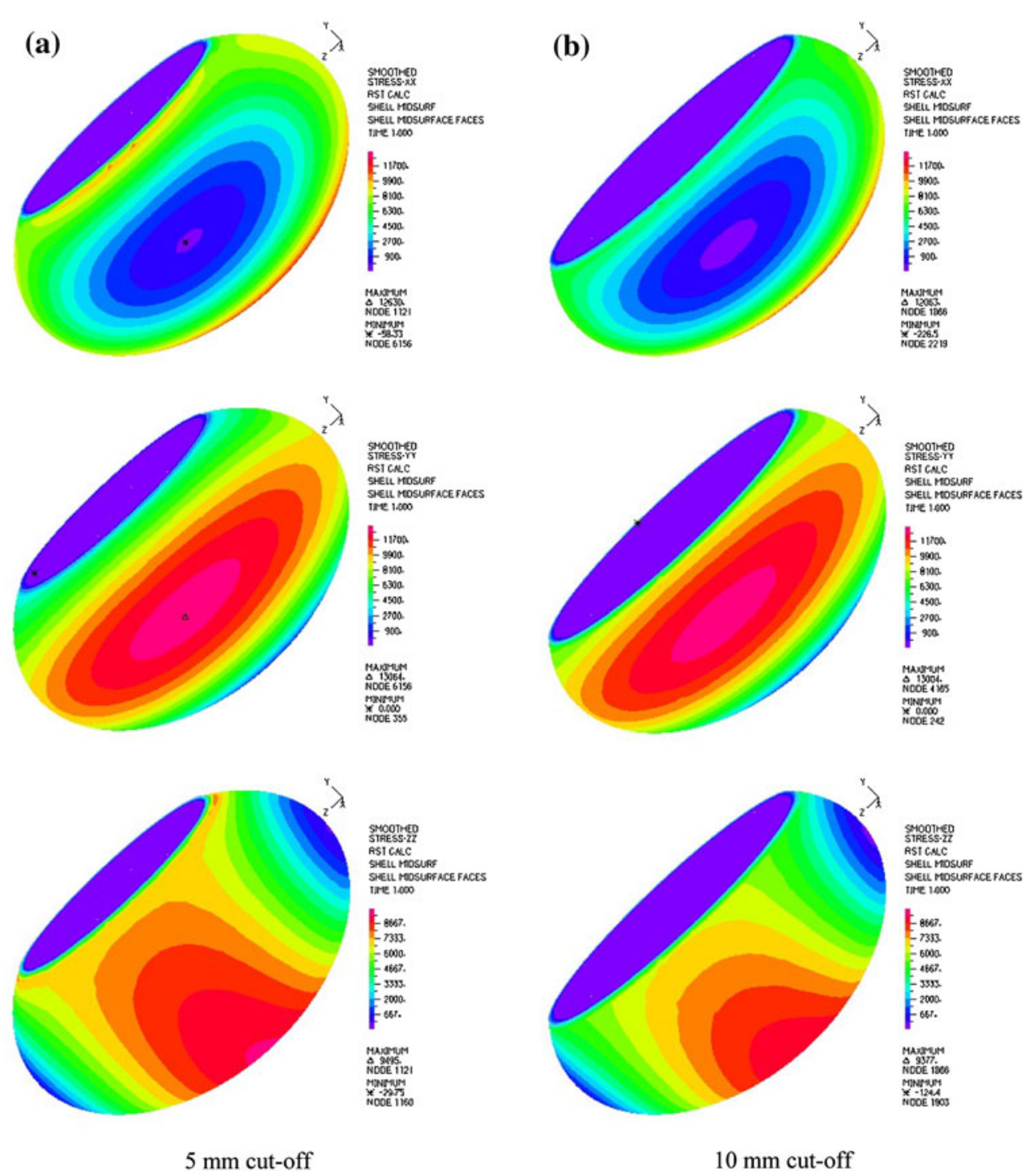

FIGURE 8. Numerically computed contours of passive stress components of the test gallbladder model with a flat top: (a) 5-mm cut, and (b) 10-mm cut from the apex along the minor axis. Top panel: $\sigma_{\mathrm{xx}}$, middle panel: $\sigma_{\mathrm{yy}}$ and bottom panel: $\sigma_{\mathrm{zz}}$.

from the subjects. The pain score (VAS: visual analogue scale $)^{22}$ based on McGill Pain Questionnaire ${ }^{30}$ was applied to specify the gallbladder pain level. Note the physical pain threshold is given by the patients themselves by ticking the 'pain/not pain' box in the questionnaire, and the scores indicating the severity of the pain are quite scattered within a 100-point scale. As these scores are highly subjective, in the following, we will evaluate the stress prediction on a clear-cut basis of 'pain/not pain', not on the severity of the pain.

The results shown in Table 2 are those obtained if we choose $[\sigma]=175 \mathrm{mmHg}$. This gives a success rate (number of subjects whose pain was correctly predicted over total number of subjects) of $75 \%$ if the peak total stress criterion is used. By comparison, the success rate of $E F$ is rather poor if we use the threshold of $35 \%$. This is consistent with earlier results from $\mathrm{Li}$ et al. ${ }^{25}$

Since the stress threshold was based on an average value for 33 patients subject to pain in the common bile duct due to a pressure increase, it is important that a small difference in this value does not have a huge impact on the overall success rate. If we shift the threshold by $\pm 10 \%$ from the default value of $175 \mathrm{mmHg}$, i.e. using $[\sigma]=192.5 \mathrm{mmHg}$, and 157.5 $\mathrm{mmHg}$, respectively, then the success rate is correspondingly changed to $71.2 \%$ and $76.9 \%$. Thus, a small shift in the stress pain threshold does not alter the conclusion that the peak stress robustly presents the strongest correlation with the physical symptom of 'pain' that patients experienced.

The counts of success and failure against the CCKinduced pain are shown in the $2 \times 2$ contingency table, 
A Mechanical Model for CCK-Induced Acalculous Gallbladder Pain

TABLE 2. Parameters and predictions for 51 acalculous gallbladders.

\begin{tabular}{|c|c|c|c|c|c|c|c|}
\hline No. & $k_{1}, k_{2}, D_{3}(\mathrm{~mm})$ & EF (\%) & $\begin{array}{c}\text { Peak } \\
\text { pressure } \\
(\mathrm{mmHg})\end{array}$ & $\begin{array}{c}\text { Peak } \\
\text { total stress } \\
(\mathrm{mmHg})\end{array}$ & $\begin{array}{c}\text { Peak } \\
\text { passive stress } \\
(\mathrm{mmHg})\end{array}$ & $\begin{array}{c}\text { Peak } \\
\text { active stress } \\
(\mathrm{mmHg})\end{array}$ & CCK test \\
\hline 1 & $0.26,0.31,72.4$ & $4.5(+)$ & 15.2 & 111 & 111 & 19 & No pain \\
\hline 2 & $0.50,0.59,59.7$ & $5.4(+)$ & $19.4(+)$ & 128 & 73 & 56 & No pain \\
\hline 3 & $0.36,0.36,72.2$ & $11.4(+)$ & 16.4 & 94 & 57 & 37 & No pain \\
\hline 4 & $0.57,0.61,57.5$ & $15.5(+)$ & $20.4(+)$ & 119 & 64 & 55 & No pain \\
\hline 5 & $0.22,0.28,74.1$ & $10.7(+)$ & 14.4 & $202(+)$ & 154 & 48 & Pain \\
\hline 6 & $0.30,0.41,68.8$ & $10.0(+)$ & 16.4 & $204(+)$ & 137 & 67 & Pain \\
\hline 7 & $0.43,0.55,57.3$ & $14.0(+)$ & $16.9(+)$ & 131 & 123 & 46 & No pain \\
\hline 8 & $0.40,0.54,66.7$ & $21.9(+)$ & 19.6(+) & $205(+)$ & 115 & 90 & Pain \\
\hline 9 & $0.35,0.55,61.1$ & $16.1(+)$ & $16.7(+)$ & $205(+)$ & 135 & 70 & Pain \\
\hline 10 & $0.27,0.45,69.1$ & $5.4(+)$ & 16.4 & $292(+)$ & 196 & 96 & No pain \\
\hline 11 & $0.28,0.41,82.0$ & $15.1(+)$ & $20.3(+)$ & $332(+)$ & 200 & 152 & No pain \\
\hline 12 & $0.28,0.39,68.3$ & $21.3(+)$ & $16.6(+)$ & 165 & 147 & 56 & No pain \\
\hline 13 & $0.33,0.47,63.2$ & 39.7 & 16.2 & $194(+)$ & 134 & 62 & Pain \\
\hline 14 & $0.29,0.55,63.5$ & $20.6(+)$ & 16.5 & $287(+)$ & 191 & 96 & Pain \\
\hline 15 & $0.35,0.42,72.0$ & 80.8 & $18.4(+)$ & 153 & 91 & 61 & Pain \\
\hline 16 & $0.29,0.34,50.7$ & $32.3(+)$ & $16.6(+)$ & 76 & 76 & 13 & No pain \\
\hline 17 & $0.40,0.46,57.5$ & $32.4(+)$ & $16.6(+)$ & 79 & 64 & 27 & Pain \\
\hline 18 & $0.29,0.32,71.6$ & 93.7 & 15.9 & 72 & 64 & 22 & Pain \\
\hline 19 & $0.38,0.39,92.3$ & 49.4 & $26.3(+)$ & $175(+)$ & 73 & 102 & Pain \\
\hline 20 & $0.41,0.53,56.7$ & 48.7 & $17.2(+)$ & 89 & 57 & 32 & Pain \\
\hline 21 & $0.38,0.40,74.5$ & 66.3 & $19.5(+)$ & 109 & 63 & 47 & No pain \\
\hline 22 & $0.23,0.44,62.8$ & 54.4 & 15.0 & $235(+)$ & 235 & 20 & Pain \\
\hline 23 & $0.31,0.44,77.5$ & 44.7 & $19.7(+)$ & $286(+)$ & 160 & 126 & Pain \\
\hline 24 & $0.41,0.52,63.0$ & $27.4(+)$ & $18.3(+)$ & 153 & 92 & 61 & No pain \\
\hline 25 & $0.38,0.50,75.4$ & $27.9(+)$ & $21.9(+)$ & $241(+)$ & 121 & 120 & Pain \\
\hline 26 & $0.32,0.41,75.8$ & 19.1(+) & $18.7(+)$ & $204(+)$ & 120 & 84 & Pain \\
\hline 27 & $0.38,0.42,64.8$ & 70.2 & $16.9(+)$ & 92 & 67 & 32 & Pain \\
\hline 28 & $0.38,0.41,68.0$ & 71.5 & $17.7(+)$ & 93 & 57 & 35 & No pain \\
\hline 29 & $0.50,0.52,56.1$ & 37.8 & $17.1(+)$ & 86 & 55 & 31 & No pain \\
\hline 30 & $0.32,0.39,71.2$ & 91.8 & $17.8(+)$ & $178(+)$ & 110 & 68 & Pain \\
\hline 31 & $0.26,0.39,74.2$ & 100 & 16.5 & 292(+) & 194 & 98 & Pain \\
\hline 32 & $0.31,0.37,71.5$ & $10.1(+)$ & $16.6(+)$ & 167 & 110 & 56 & No pain \\
\hline 33 & $0.41,0.48,63.0$ & 95 & $17.6(+)$ & 120 & 78 & 42 & No pain \\
\hline 34 & $0.27,0.44,67.0$ & 82.6 & 15.9 & $270(+)$ & 187 & 83 & Pain \\
\hline 35 & $0.38,0.53,45.8$ & 100 & 13.6 & 103 & 86 & 19 & Pain \\
\hline 36 & $0.30,0.34,76.1$ & $16.3(+)$ & $17.1(+)$ & 141 & 91 & 50 & No pain \\
\hline 37 & $0.56,0.57,53.8$ & 77 & $17.7(+)$ & 100 & 62 & 38 & No pain \\
\hline 38 & $0.37,0.47,69.5$ & $10.7(+)$ & $18.9(+)$ & $182(+)$ & 106 & 76 & Pain \\
\hline 39 & $0.51,0.53,57.3$ & $8.0(+)$ & $19.0(+)$ & 103 & 60 & 43 & Pain \\
\hline 40 & $0.25,0.27,73.1$ & $22.2(+)$ & 14.8 & 101 & 101 & 24 & Pain \\
\hline 41 & $0.44,0.47,55.4$ & 36.4 & 16.2 & $236(+)$ & 201 & 35 & Pain \\
\hline 42 & $0.46,0.46,82.1$ & $2.8(+)$ & $26.7(+)$ & $182(+)$ & 75 & 107 & No pain \\
\hline 43 & $0.23,0.37,88.6$ & $14.2(+)$ & $19.1(+)$ & $473(+)$ & 272 & 201 & Pain \\
\hline 44 & $0.24,0.29,81.5$ & $15.2(+)$ & 16.0 & $223(+)$ & 188 & 70 & No pain \\
\hline 44 & $0.41,0.48,57.5$ & $9.1(+)$ & 16.0 & 96 & 66 & 30 & No pain \\
\hline 46 & $0.45,0.52,60.0$ & $6.5(+)$ & $17.6(+)$ & 107 & 67 & 40 & No pain \\
\hline 47 & $0.32,0.39,70.5$ & $34.4(+)$ & $17.1(+)$ & 166 & 107 & 59 & No pain \\
\hline 48 & $0.35,0.57,61.2$ & $0.1(+)$ & $17.1(+)$ & $223(+)$ & 143 & 80 & Pain \\
\hline 49 & $0.29,0.43,57.3$ & $1.25(+)$ & 14.2 & $181(+)$ & 141 & 40 & Pain \\
\hline 50 & $0.47,0.44,71.9$ & $8.75(+)$ & $21.2(+)$ & 147 & 62 & 85 & No pain \\
\hline 51 & $0.38,0.64,55.1$ & $1.62(+)$ & 16.5 & $192(+)$ & 128 & 64 & Pain \\
\hline \multicolumn{2}{|c|}{ Threshold } & {$[E F]=0.35$} & {$[p]=16.6 \mathrm{mmHg}$} & {$[\sigma]=175 \mathrm{mmHg}$} & & & \\
\hline \multicolumn{2}{|c|}{ Success rate } & $21 / 51=0.412$ & $21 / 51=0.412$ & $39 / 51=0.765$ & & & \\
\hline
\end{tabular}

Note: $[E F]=0.35$ is commonly used clinical threshold, and $[p]=16.6 \mathrm{mmHg}$ is an average value of pressure estimated at $E F=0.35 \mathrm{from}$ the 51 samples. Note the success rate for each of $[E F],[p]$ and $[\sigma]$ thresholds is defined as the number of subjects whose pain was correctly predicted over total number of subjects, and the + sign indicates that the quantity is over the 'threshold' for pain. 
TABLE 3. Statistics showing outcome of positive and negative predictions against physical symptom of 'pain' based on the stress prediction, $[\sigma]=175 \mathrm{mmHg}$.

\begin{tabular}{lll}
\hline & \multicolumn{1}{c}{$\begin{array}{c}\text { Against the physical pain induced } \\
\text { by CCK }\end{array}$} \\
\cline { 2 - 3 } & \multicolumn{1}{c}{$\begin{array}{c}\text { Positive } \\
\text { (pain) }\end{array}$} & \multicolumn{1}{c}{$\begin{array}{c}\text { Negative } \\
\text { (no pain) }\end{array}$} \\
\hline Parameter & $20(0.74)$ & $19(0.792)$ \\
Success & $7(0.26)$ & $5(0.208)$ \\
$\begin{array}{l}\text { Failure } \\
\text { Sample size }\end{array}$ & 27 & 24 \\
$\begin{array}{l}\text { Confidence interval (95\%) } \\
\text { Ratio of odds } \\
\quad \text { positive/negative) }\end{array}$ & $(0.547,0.871)$ & $(0.587,0.911)$ \\
$\begin{array}{l}\text { Asymptotic standard error } \\
\text { Confidence interval (95\%) } \\
\text { of the ratio }\end{array}$ & -0.752 & \\
\hline
\end{tabular}

(Table 3), together with the statistics using the logistic transformation. ${ }^{25}$ Table 3 shows that the success rate of positive prediction $(0.74)$ is now slightly lower than that of negative prediction (0.792), with the ratio of odds (positive/negative) less than one (0.752). This is different from the previous observation based on a smaller sample size,${ }^{25}$ when a slightly higher positive prediction was shown. However, the difference is not significant, and the overall success rate is very similar $(76 \%)$.

\section{DISCUSSION}

In this study, we have extended our mechanical model to account properly for both active and passive stress, by considering isotonic refilling and isometric contraction of the gallbladder wall during the CCK test. The model is applied to a larger sample size (51) and the results again strongly support our hypothesis that the peak total (active + passive) stress inside the gallbladder wall over a threshold is associated with CCK-induced gallbladder pain.

Our model relies on the volume estimation from ultrasound measurement, when gallbladder is assumed as an ellipsoid. It is natural to ask how the accuracy of the volume measurement influences the model outcome. It has been reported that this kind of volume estimate may induce an error of about $12.5 \%{ }^{38}$ Such an error is equivalent to an error of $4.2 \%$ in each dimension of $D_{1}, D_{2}$, and $\mathrm{D}_{3}$. Taken a particular sample, say, GB 37, if $D_{1}, D_{2}$, and $\mathrm{D}_{3}$ vary by $\pm 4.2 \%$, then the peak total stress will change of about $-8.6 \sim 9.85 \%$. However, since we have validated the model prediction by allowing a $\pm 10 \%$ variation in the stress threshold (see "Gallbladder Pain Prediction" section), the issue of the inaccuracy of the volume estimation has been addressed.

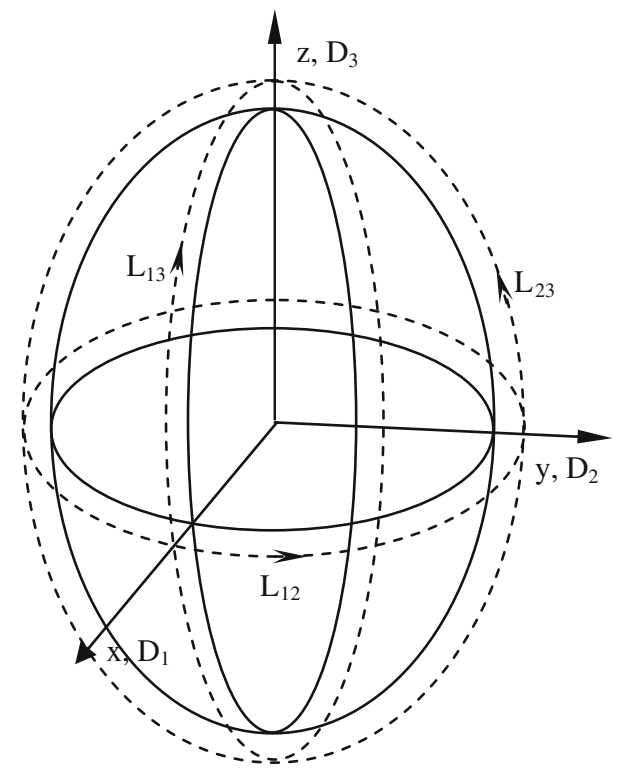

FIGURE 9. The locations of the arc-lengths, $L_{12}, L_{23}$ and $L_{13}$, in the $x y$-, $y x$ - and $x z$-planes, respectively.

It has been shown experimentally that the circumferential strain is responsible for the pain in human oesophagus, ${ }^{2}$ duodenum ${ }^{15}$ and rectum. ${ }^{39}$ It is believed that the mechanoreceptors in the wall of those organs are the (circumferential) strain rather than the total or passive tension. For the human duodenum in an active state, the strain threshold for pain in the circumferential direction is found to be $1.1 \pm 0.2 .{ }^{15}$ Similar observations were seen in the human gastrointestinal pain. ${ }^{11}$ It is likely that the pain receptors in the nerves respond to the muscle strain. Although the structure of the gallbladder is quite different to these organs, the fact that the strain and stress are directly related provides the rationale for the success of our model. Although we cannot determine the local strain based on the ultrasonographical images because the material points were not tracked, it is possible to estimate the mean strains of the GB model by monitoring the change of the arc-lengths $L_{12}, L_{23}$ and $\mathrm{L}_{13}$ in the $x y$ - $\left(D_{1}-D_{2}\right), y z-\left(D_{2}-D_{3}\right)$ and $x z-\left(D_{1}-D_{3}\right)$ planes, respectively, (see Fig. 9). When normalized with the respect to the reference state (when $\mathrm{EF}=70 \%$ ), the strains are estimated as:

$$
\left\{\begin{array}{l}
\varepsilon_{12}=L_{12} / L_{12 \mathrm{ref}}-1=2 \pi\left(\frac{D_{1}^{1.5}+D_{2}^{1.5}}{2^{2.5}}\right)^{1 / 1.5} / L_{12 \mathrm{ref}}-1 \\
\varepsilon_{23}=L_{23} / L_{23 \mathrm{ref}}-1=2 \pi\left(\frac{D_{2}^{1.5}+D_{3}^{1.5}}{2^{2.5}}\right)^{1 / 1.5} / L_{12 \mathrm{ref}}-1 . \\
\varepsilon_{13}=L_{13} / L_{13 \mathrm{ref}}-1=2 \pi\left(\frac{D_{1}^{1.5}+D_{3}^{1.5}}{2^{2.5}}\right)^{1 / 1.5} / L_{12 \mathrm{ref}}-1
\end{array}\right.
$$

The arc length is based on the formulas by Almkvist and Berndt. ${ }^{1}$ Applying (15) to the 51 samples, we 
found that most of these values are much smaller than the threshold of $1.1 \pm 0.2$ found for human duodenum. ${ }^{15}$ Even if we increase the pain threshold to, say $[\varepsilon]=0.55$, the success rate is still only 0.569 . This suggests that the mean strains are not useful indicators for the gallbladder pain, and highlights the importance of the spatial distribution. This spatial dependence is reflected in our stress prediction, even though it is only for an ellipsoidal model.

Importantly, the simple and straightforward stress prediction presented here is derived from non-invasive volume measurements only. Since strains cannot be measured non-invasively, and there are very few other reliable alternatives for gallbladder pain prediction, this approach has potential clinical significance for the assessment of patients with acalculous biliary pain. These patients represent a significant portion of the 50,000 patients who undergo cholecystectomy each year in the UK.

The mechanical model as it stands inevitably suffers from several oversimplifications, for instance, that the wall of the gallbladder is an ellipsoidal membrane of uniform thickness, that the tissue is linearly elastic, that the compliance of the gallbladder is constant and that there is a single constant pain threshold for all patients. Patient-specific data such as age, sex and obesity are not included in this model. It will be of interest to learn more about the nonlinear behaviour of human gallbladder tissue, the patient-specific material properties and complicated geometries, as well as the pain mechanisms at the microstructure level of the muscle wall.

Predicting pain accurately based entirely on mathematical modelling is an ambitious task, for pain can be very subjective, and the mechanisms for repeated attacks in the longer term may be very different from the instantaneous pain triggered by CCK. The current study is only the first step towards developing a scientifically sound model which can take into account of mechanical responses, patient-specific geometry based on MRI, tissue growth, response to drugs, diet, presence of gallstones, and hormone changes, and ultimately has the power to predict who will not benefit from cholecystectomy.

\section{CONCLUSIONS}

The behaviour of a gallbladder in the CCK provocation test can be described by the isotonic refilling, isometric contraction and emptying phases. Based on a mechanical model initially developed by Li et al., ${ }^{25}$ we investigated the total (passive plus active) stresses of acalculous gallbladders during a CCK provocation test. By assuming the gallbladder to be a thin-walled ellipsoid under internal pressure, we are able to predict the three-dimensional stress distribution during gallbladder emptying using a closed-form analytical solution. To assess the effect of a non-ellipsoidal change of the gallbladder shape on the peak stress, such as the attachment to the liver, we also performed numerical simulations for a test gallbladder model with and without a cut-off plane from the ellipsoid top. Although there are stress concentrations near the cutoff plane, the peak stresses as well as the stress contours away from the top plane are very similar to those without the cut. The prediction of the CCK-induced pain using the stress model for a chosen pain threshold (with $10 \%$ shift either way) agrees with over $75 \%$ of the clinical verdicts based on the McGill Pain Questionnaire for 51 subjects. As the model is very simple and relies only on non-invasive volume measurements, it can be readily used as part of the clinical assessment or follow up without extra costs. In the future, this model has the potential to be an additional diagnostic tool to aid clinicians in determining if a patient will benefit from cholecystectomy.

\section{APPENDIX: GRID INDEPENDENCE TEST FOR THE ADINA NUMERICAL MODEL}

\begin{tabular}{|c|c|c|c|c|}
\hline Element & $\begin{array}{c}\text { Mesh size (mm) } \\
\text { (length of an edge) }\end{array}$ & $\begin{array}{c}\text { Peak } \\
\sigma_{x x}(\mathrm{~Pa}) \\
\end{array}$ & $\begin{array}{c}\text { Peak } \\
\sigma_{\mathrm{yy}}(\mathrm{Pa}) \\
\end{array}$ & $\begin{array}{c}\text { Peak } \\
\sigma_{\mathrm{zz}}(\mathrm{Pa}) \\
\end{array}$ \\
\hline \multirow[t]{3}{*}{ 4-node quad } & 0.75 & 9607 & 13,179 & 13,178 \\
\hline & $\begin{array}{l}1.0 \text { (the chosen } \\
\text { grid) }\end{array}$ & 9607 & 13,175 & 13,172 \\
\hline & 1.25 & 9602 & 13,168 & 13,166 \\
\hline 8-node quad & 1.0 & 9612 & 13,192 & 13,189 \\
\hline Triangle & 1.0 & 9609 & 13,186 & 13,185 \\
\hline
\end{tabular}

Note that the effect of choosing different types of element is equivalent to choosing one type of element and different grid points. The test shows that the peak stress components do not change significantly when using different grids, therefore the 4-node quadrilateral element with 1-mm mesh size was chosen for the final results.

\section{ACKNOWLEDGMENT}

The project was supported by EPSRC through grant $\mathrm{EP} / \mathrm{G} 015651$.

\section{REFERENCES}

\footnotetext{
${ }^{1}$ Almkvist, G., and B. Berndt. Gauss, Landen, Ramanujan, the arithmeticgeometric mean, ellipses, $\pi$ and the ladies diary. Am. Math. Mon. 95:585-608, 1988.
} 
${ }^{2}$ Barlow, J., H. Gregersen, et al. Identification of the biomechanical factors associated with the perception of distension in the human esophagus. Am. J. Physiol. Gastrointest. Liver Physiol. 282(4):683-689, 2002.

${ }^{3}$ Bathe, K. J. Finite Element Procedures. Englewood Cliffs, NJ: Prentice Hall, 1996.

${ }^{4}$ Beckingham, I. J. ABC of diseases of liver, pancreas, and biliary system: gallstone disease. Br. Med. J. 322(7278):91, 2001.

${ }^{5}$ Body, L., L. Højgaard, et al. Human gallbladder pressure and volume: validation of a new direct method for measurements of gallbladder pressure in patients with acute cholecystitis. Clin. Physiol. Funct. Imaging 16(2):145-156, 2008.

${ }^{6}$ Brotschi, E., K. Crocker, et al. Effect of low extracellular calcium on gallbladder contractionin vitro. Dig. Dis. Sci. 34(3):360-366, 1989

${ }^{7}$ Chijiiwa, K., T. Yamasaki, et al. Direct contractile response of isolated gallbladder smooth muscle cells to cholecystokinin in patients with gallstones. J. Surg. Res. 56(5):434-438, 1994.

${ }^{8}$ Claus, P., M. McLaughlin, et al. Estimation of active myocardial force development: a feasibility study in a potentially clinical setting. Proceedings of the 25th Annual International Conference of the IEEE EMBS, Cancun, Mexico, September 17-21, 2003.

${ }^{9}$ Cozzolino, H., F. Goldstein, et al. The cystic duct syndrome. JAMA 185(12):920, 1963.

${ }^{10}$ Dodds, W. J., W. J. Hogan, et al. Motility of the biliary system. In: Handbook of Physiology: the Gastrointestinal System, Vol. 1, Section 6, Part 2(28), edited by S. G. Schultz. Betheda, Maryland: American Physiological Society, 1989, pp. 1055-1101.

${ }^{11}$ Drewes, A., H. Gregersen, et al. Experimental pain in gastroenterology: a reappraisal of human studies. Scand. J. Gastroenterol. 38(11):1115-1130, 2003.

${ }^{12}$ Ferris, D., and J. Vibert. The common bile duct: significance of its diameter. Ann. Surg. 149(2):249-251, 1959.

${ }^{13}$ Fuller, R. A., J. A. Kuhn, et al. Laparoscopic cholecystectomy for acalculous gallbladder disease. Proc. (Bayl. Univ. Med. Cent.) 13(4):331-333, 2000.

${ }^{14}$ Gaensler, E. Quantitative determination of the visceral pain threshold in man. J. Clin. Invest. 30:406, 1951.

${ }^{15}$ Gao, C., L. Arendt-Nielsen, et al. Sensory and biomechanical responses to ramp-controlled distension of the human duodenum. Am. J. Physiol. Gastrointest. Liver Physiol. 284(3):461, 2003.

${ }^{16}$ Herman, I. P. Physics of the Human Body. Berlin: Springer, p. 214, 2007.

${ }^{17}$ Herring, P., and S. Simpson. The pressure of bile secretion and the mechanism of bile absorption in obstruction of the bile duct. Proc. R. Soc. Lond., B, Biol. Sci. 79(535):517-532, 1907.

${ }^{18}$ Hould, F. S., G. M. Fried, et al. Progesterone receptors regulate gallbladder motility. J. Surg. Res. 45(6):505-512, 1988.

${ }^{19}$ Hunter, P., and B. Smaill. The analysis of cardiac function: a continuum approach. Prog. Biophys. Mol. Biol. 52(2): 101-164, 1988.

${ }^{20}$ Ishizuka, J., M. Murakami, et al. Age-related changes in gallbladder contractility and cytoplasmic $\mathrm{Ca}^{2+}$ concentration in the guinea pig. Am. J. Physiol. Gastrointest. Liver Physiol. 264(4):624, 1993.

${ }^{21}$ Lambert, R., and J. Ryan. Response to calcium of skinned gallbladder smooth muscle from newborn and adult guinea pigs. Pediatr. Res. 28(4):336, 1990.
${ }^{22}$ Langley, G. B., and H. Sheppeard. The visual analogue scale: its use in pain measurement. Rheumatol. Int. 5(4): 145-148, 1985.

${ }^{23}$ Lee, K., P. Biancani, et al. Calcium sources utilized by cholecystokinin and acetylcholine in the cat gallbladder muscle. Am. J. Physiol. Gastrointest. Liver Physiol. 256(4): $785,1989$.

${ }^{24} \mathrm{Li}$, W. G., X. Y. Luo, et al. One-dimensional models of the human biliary system. J. Biomech. Eng.-Trans. ASME 129(2):164-173, 2007.

${ }^{25} \mathrm{Li}$, W. G., X. Y. Luo, et al. Correlation of mechanical factors and gallbladder pain. Comput. Math. Methods Med. 9(1):27-45, 2008.

${ }^{26}$ Luo, X. Y., W. G. Li, et al. On the mechanical behaviour of the human biliary system. World J. Gastroenterol. 13:13841392, 2007.

${ }^{27}$ MacPherson, B., G. Scott, et al. The muscle layer of the canine gallbladder and cystic duct. Cells Tissues Organs 120(3):117-122, 1984.

${ }^{28}$ Mahour, G., K. Wakim, et al. The common bile duct in man: its diameter and circumference. Ann. Surg. 165(3): 415, 1967.

${ }^{29}$ Meiss, R. Graded activation in rabbit mesotubarium smooth muscle. Am. J. Physiol. 229(2):455, 1975.

${ }^{30}$ Melzack, R. The McGill Pain Questionnaire: major properties and scoring methods. Pain 1(3):277-299, 1975.

${ }^{31}$ Middelfart, H. V., P. Jensen, et al. Pain patterns after distension of the gallbladder in patients with acute cholecystitis. Scand. J. Gastroenterol. 33(9):982-987, 1998.

${ }^{32}$ Morales, S., P. Camello, et al. Characterization of intracellular $\mathrm{Ca}^{2+}$ stores in gallbladder smooth muscle. Am. J. Physiol. Gastrointest. Liver Physiol. 288(3):G507, 2005.

${ }^{33}$ Ness, T. J., and G. F. Gebhart. Visceral pain: a review of experimental studies. Pain 41(2):167-234, 1990.

${ }^{34}$ Novozhilov, V. V. Thin Shell Theory. Groningen: P. Noordhoff Ltd, pp. 124-1130, 1964.

${ }^{35}$ Ooi, R. C., X. Y. Luo, et al. The flow of bile in the human cystic duct. J. Biomech. 37(12):1913-1922, 2004.

${ }^{36}$ Parkman, H., A. Pagano, et al. Electric field stimulationinduced guinea pig gallbladder contractions (role of calcium channels in acetylcholine release). Dig. Dis. Sci. 42(9):1919-1925, 1997.

${ }^{37}$ Parkman, H., R. Garbarino, et al. Myosin light chain phosphorylation correlates with contractile force in guinea pig gallbladder muscle. Dig. Dis. Sci. 46(1):176-181, 2001.

${ }^{38}$ Pauletzki, J., M. Sackmann, et al. Evaluation of gallbladder volume and emptying with a novel three-dimensional ultrasound system: comparison with the sum-of-cylinders and the ellipsoid methods. J. Clin. Ultrasound 24(6):277285, 1996.

${ }^{39}$ Petersen, P., C. Gao, et al. Pain intensity and biomechanical responses during ramp-controlled distension of the human rectum. Dig. Dis. Sci. 48(7):1310-1316, 2003.

${ }^{40}$ Renzetti, L., M. Wang, et al. Contribution of intracellular calcium to gallbladder smooth muscle contraction. Am. J. Physiol. Gastrointest. Liver Physiol. 259(1):G1, 1990.

${ }^{41}$ Ryan, J. Calcium and gallbladder smooth muscle contraction in the guinea pig: effect of pregnancy. Gastroenterology 89(6): 1279, 1985.

${ }^{42}$ Ryan, J., and S. Cohen. Gallbladder pressure-volume response to gastrointestinal hormones. Am. J. Physiol. 230(6):1461, 1976.

${ }^{43}$ Schoetz, Jr., D., W. LaMorte, et al. Mechanical properties of primate gallbladder: description by a dynamic method. Am. J. Physiol. Gastrointest. Liver Physiol. 241(5):376, 1981. 
${ }^{44}$ Shaffer, E. A. Epidemiology of gallbladder stone disease. Best Pract. Res. Clin. Gastroenterol. 20(6):981-996, 2006.

${ }^{45}$ Shaffer, E., A. Bomzon, et al. The source of calcium for CCK-induced contraction of the guinea-pig gallbladder. Regul. Pept. 37(1):15-26, 1992.

${ }^{46}$ Shimada, T. Voltage-dependent calcium channel current in isolated gallbladder smooth muscle cells of guinea pig. Am. J. Physiol. Gastrointest. Liver Physiol. 264(6):1066, 1993.

${ }^{47}$ Shoucri, R. Theoretical study of pressure-volume relation in left ventricle. Am. J. Physiol. Heart Circ. Physiol. 260(1): H282, 1991.

${ }^{48}$ Shoucri, R. Studying the mechanics of left ventricular contraction. IEEE Eng. Med. Biol. Mag. 17(3):95-101, 1998.

${ }^{49}$ Shoucri, R. Active and passive stresses in the myocardium. Am. J. Physiol. Heart Circ. Physiol. 279(5):H2519, 2000.

${ }^{50}$ Smythe, A., A. Majeed, et al. A requiem for the cholecystokinin provocation test? Gut 43(4):571, 1998.

${ }^{51}$ Smythe, A., R. Ahmed, et al. Bethanechol provocation testing does not predict symptom relief after cholecystectomy for acalculous biliary pain. Dig. Liver Dis. 36(10):682-686, 2004.

${ }^{52}$ Streeter, Jr., D., R. Vaishnav, et al. Stress distribution in the canine left ventricle during diastole and systole. Biophys. J. 10(4):345-363, 1970.

${ }^{53}$ Washabau, R., M. Wang, et al. Effect of muscle length on isometric stress and myosin light chain phosphorylation in gallbladder smooth muscle. Am. J. Physiol. Gastrointest. Liver Physiol. 260(6):920, 1991.

${ }^{54}$ Washabau, R., M. Wang, et al. Role of myosin light-chain phosphorylation in guinea pig gallbladder smooth muscle contraction. Am. J. Physiol. Gastrointest. Liver Physiol. 266(3):G469, 1994.

${ }^{55}$ Williamson, R. Acalculous disease of the gallbladder. Gut 29(6):860, 1988.

${ }^{56}$ Yamasaki, T., K. Chijiiwa, et al. Direct contractile effect of motilin on isolated smooth muscle cells from human gallbladder. J. Surg. Res. 56(1):89-93, 1994.

${ }^{57}$ Zhang, L., A. Bonev, et al. Ionic basis of the action potential of guinea pig gallbladder smooth muscle cells. Am. J. Physiol., Cell Physiol. 265(6):C1552, 1993. 